This is a repository copy of. "Gain-scheduling model predictive control of a Fresnel collector field" in the Depósito de Investigación de la Universidad de Sevilla

Version: Author Accepted Version

Citation: Antonio J. Gallego, Gonzalo M. Merello, Manuel Berenguel \& Eduardo F. Camacho. "Gain-scheduling model predictive control of a Fresnel collector field". Control Engineering Practice - ISSN 0967-0661. Vol.:82, pp. 1-13. Enero 2019. 10.1016/j.conengprac.2018.09.022

To cite this publication, please use the final published version (if applicable). Please check the document version above.

Copyright: Other than for strictly personal use, it is not permitted to download, forward or distribute the text or part of it, without the consent of the author(s) and/or copyright holder(s), unless the work is under an open content license such as Creative Commons.

Takedown policy: Please contact us (idus@us.es) and provide details if you believe this document breaches copyrights. We will remove access to the work immediately and investigate your claim 


\title{
Gain-Scheduling Model Predictive Control of a Fresnel Collector Field
}

\author{
Antonio J. Gallego ${ }^{\mathrm{a}}$, Gonzalo M. Merello ${ }^{\mathrm{a}}$, Manuel Berenguel ${ }^{\mathrm{b}}$, Eduardo F. Camacho ${ }^{\mathrm{a}}$ \\ ${ }^{a}$ Departamento de Ingeniería de Sistemas y Automática, Universidad de Sevilla, Camino de los Descubrimientos s/n., 41092 Sevilla, Spain \\ ${ }^{b}$ Centro Mixto CIESOL, ceiA3, Departamento de Informática, Universidad de Almería. Ctra. Sacramento s/n, 04120, Almería, Spain
}

\begin{abstract}
Model predictive control strategies have been applied successfully when controlling solar plants. If the control algorithm uses a linear model associated only to an operating point, when the plant is working far from the design conditions, the performance of the controller may deteriorate.

In this paper, a gain scheduling model predictive control strategy is designed for the Fresnel collector field located at the Escuela Superior de Ingenieros de Sevilla. Simulation results are provided comparing the proposed strategy with another linear MPC controller showing a better performance. Furthermore, two real tests are presented showing the effectiveness of the proposed strategy.
\end{abstract}

Keywords: Solar energy, Fresnel collector, Gain Scheduling, Model Predictive Control

\section{Introduction}

Interest in renewable energy sources such as solar energy experienced a great impulse after the Big Oil Crisis in the 70s. Driven mainly by economic factors, this interest decreased when oil prices fell. Nowadays, there is a renewed interest in renewable energies spurred by the need to reduce the environmental impact produced by the use of fossil energy systems (Goswami et al. (2000); Camacho and Berenguel (2012)). Solar energy is, by far, the most abundant source of renewable energy. In fact, wind and most of the hydraulic energies come from solar energy (Camacho and Gallego (2013)).

Many solar energy plants have been commissioned in the last 15 years. The three $50 \mathrm{MW}$ Solnova and the two 50 MW Helioenery parabolic trough plants of Abengoa in Spain can be mentioned as examples, as well as the SOLANA and Mojave Solar parabolic trough plants constructed in Arizona and California, each of 280 MW power production (Yield (2017)). Examples of solar tower plants are plants PS10 and PS20 in Southern Spain of 10 MW and 20 MW respectively. In 2016, the $50 \mathrm{MW}$ solar tower plant Khi Solar One operated by Abengoa Solar was commissioned in South Africa (Abengoa (2017)).

Email addresses: gal legolen@ hotmail . com (Antonio J. Gallego), gonzalo.monguio@gmail . com (Gonzalo M. Merello), beren@ual .es (Manuel Berenguel), eduardo@esi.us.es (Eduardo F. Camacho)

${ }^{1}$ phone/fax number: +34954487347

Preprint submitted to Control Engineering Practice
One of the main applications of solar energy is the production of electricity. For example, in parabolic trough plants the solar radiation coming from the sun is focused onto a metal tube where a fluid is circulating. The fluid is heated up and then used in a steam generator to produce electricity (Camacho et al. (1997): Camacho et al. (2011)). Another application of solar energy is the supply of air conditioning in buildings. The interest in solar cooling systems has been increasing for several decades, driven by the fact that the need for air conditioning is usually well correlated to solar radiation (Sonntag et al. (2008): Kima and Infante-Ferreira (2008)).

This paper deals with the control of a Fresnel collector field which belongs to the solar cooling plant located on the roof of the Engineering School (ESI) of Seville (Bermejo et al. (2010)). The plant was commissioned in 2008, consisting of a Fresnel collector field, a double effect $\mathrm{LiBr}+$ water absorption chiller and a storage tank. The Fresnel collector delivers pressurized water at $140-170{ }^{\circ} \mathrm{C}$ to the absorption machine for producing air conditioning. If solar radiation is not high enough for heating the water up to the required temperature, the storage tank may be used. If neither the solar field nor the storage tank are able to heat up the water to the operation temperature, the absorption machine must resort to burning natural gas.

In (Witheephanich et al. (2013): Witheephanich. et al. (2014)) possible control approaches for this kind of plant are discussed, showing simulation results of the 
application of an explicit model predictive control. Similar facilities have been deployed in other places (Döll et al. (2014):Zhou et al. (2017)).

Regarding similar applications for buildings, in (Berger et al. (2012)) a prototype of a linear Fresnel collector providing the driving heat at temperatures up to $200{ }^{\circ} \mathrm{C}$ for two cascading ammonia water absorption chillers is presented, including some experimental tests defocusing collectors. In (Häberle et al. (2007)), a linear concentrating Fresnel collector is used to drive an NH3-H20 absorption chiller, without including control issues.

Fresnel collectors are also used to feed an Organic Rankine Cycle with storage in Rodat et al. (2014). The solar plant is simulated using both oil and water/steam as heat transfer fluid. Simulations with Dymola using Modelica code are provided. Operating experiences are included in Rodat et al. (2015) using cascade PI control and a reference governor. An interesting application of building integration of Fresnel concentrators for solar cooling applications can be found in Chemisana et al. (2013).

The control objective in this kind of plant is to maintain the outlet temperature of the solar field around a desired set-point (Berenguel et al.(2005)). Many works related to the control of solar plants have been developed and published since 1980. Most of them were tested in the parabolic trough ACUREX solar collector field. This trough plant consisted of a field of solar collectors, a heat storage system and an electrical conversion unit (0.5 MW Stal Laval turbine) (Carmona (1985)). In (Camacho et al. (2007): Camacho et al. (2007b) Rubio et al. (2006) ) a review of different control strategies applied to the ACUREX plant is presented. Moreover, the books by Camacho and coworkers (Camacho et al. (2012)) and Lemos and coworkers (Lemos et al. (2014)) overview different approaches related to predictive and adaptive control of this kind of system. Since a solar collector field is affected by multiple disturbance sources and its dynamics change strongly with the operating conditions (Pin et al. (2007)), conventional linear control strategies do not perform well throughout the entire range of operation, thus requiring the application of nonlinear control strategies many of them treated in Camacho et al.(2012) and Lemos et al. (2014).

In this paper a gain scheduling generalized model predictive control (henceforth GS-GPC) for a Fresnel plant is developed. Gain scheduling is a control technique where process dynamics can be associated to the value of some process variables related, in this case, to the operating point, so that the controller parame- ters can be computed from these variables. In Camacho et al. (2007b), there is a section devoted to gain scheduling summarizing the main approaches already used in the field, mainly using the actual oil flow as scheduling variable. Regarding MPC, different control approaches have also been applied in this scope and summarized in Camacho et al. (2007b), Camacho et al. (2012) and Lemos et al. (2014). As recent examples, with applications to the ACUREX field, in Limon et al. (2008) a robust MPC for tracking was designed, while in Gallego et al. (2013), an observer based MPC was developed and tested. Andrade et al. (2013) developed a practical nonlinear MPC. More recently, in Khoukhi et al. (2015) a nonlinear continuous time generalized predictive control (GPC) is developed and tested only in simulation.

The main contribution of this paper is the development of a gain scheduling model predictive control for a Fresnel collector field. The approach is similar to that proposed in Camacho et al. (1994) for a parabolic trough solar field. However there are some significant differences which are listed below:

1. The model developed is different because the controller is applied to a different type of plant. This plant is based on a Fresnel collector and not on a parabolic trough and uses water as heat transfer fluid instead of oil.

2. In the approach developed in Camacho et al. (1994), the unconstrained GPC problem was solved for 4 values of the flow. The controller gains were obtained for these four points and the control scheme interpolated the controller gains. In the MPC controller developed in this paper, the interpolation is done for the parameters of the linear model not for the solution of the GPC problem. Furthermore, the approach proposed in $\mathrm{Ca}-$ macho et al. (1994) does not solve a constrained GPC problem, as in this case.

The main drawback of using the interpolation between the controller parameters is that it provides an approximation to the global solution of the optimization problem, but for the unconstrained case. It uses the explicit solution of the GPC problem for the four considered points and interpolates among them. The approach used here, interpolating between the linear model parameters allows constraints in the GPC optimization problem to be taken into account in an easy way, and to be solved using a QP algorithm.

A simulation to compare the performance of the two approaches (for the unconstrained case) has been included. The one proposed here performs 
Table 1: List of Abbreviations

\begin{tabular}{ll}
\hline GPC & Generalized Model Predictive Control \\
GS-GPC & $\begin{array}{l}\text { Gain-Scheduling Model Predictive } \\
\text { Control }\end{array}$ \\
HTF & $\begin{array}{l}\text { Heat Transfer Fluid } \\
\text { Integral of the Square Error }\end{array}$ \\
ISE & $\begin{array}{l}\text { Integral of Time multiplied by } \\
\text { Absolute Error }\end{array}$ \\
MF-GPC & $\begin{array}{l}\text { Medium-Flow Generalized Model } \\
\text { Predictive Controller }\end{array}$ \\
MPC & Model Predictive Control \\
PCM & Phase Change Material \\
PDE & Partial Differential Equation \\
PRBS & Pseudo random binary sequence \\
\hline
\end{tabular}

slightly better as is shown in section 5 .

3. Additionally, the unconstrained GPC problem has been solved for several water flow levels considering the actual linear model associated to every point (obtained by a least square identification method). The evolution of some of the optimal controller parameters is compared to the evolution obtained by the approach presented here and the one proposed in Camacho et al. (1994). The approach proposed here is closer to the optimal evolution, especially at low flow levels.

4. Moreover, in this paper an estimation of the efficiency loss produced by the miscalibrated mirrors is carried out for the real tests. This estimation is useful for the feedforward controller which uses a better optical efficiency estimation.

The GS-GPC control strategy developed in this paper is tested using a nonlinear distributed parameter model and compared to a GPC designed for medium flow conditions (MF-GPC), showing its advantages. Two real tests carried out at the actual plant are also shown and discussed.

The paper is organized as follows: section 2 briefly describes the solar cooling plant. Section 3 presents the mathematical model of the Fresnel collector field used in this paper. Section 4 describes the design process of the proposed control strategy. Section 5 presents the simulation results and the real tests performed at the actual plant. Finally, section 6 draws to a close with concluding remarks.

\section{Brief plant description}

The solar cooling plant was commissioned in 2008 and consists of three subsystems: the double-effect
$\mathrm{LiBr}+$ water absorption chiller of $174 \mathrm{~kW}$ nominal cooling capacity. The solar Fresnel collector field which heats up the pressurized water and delivers it to the water absorption chiller. The PCM storage tank which helps to supply energy to the water to reach the required operation temperature whenever the solar field is not able to reach it. Figure 1 shows the scheme of the whole plant.

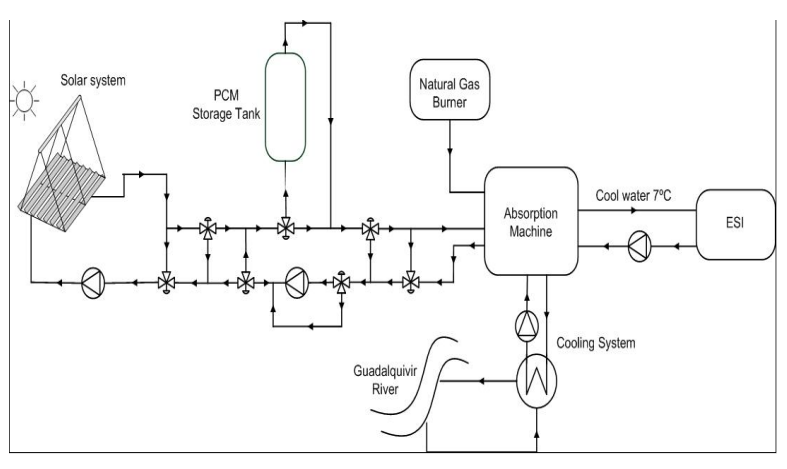

Figure 1: Plant general scheme

Water absorption chiller: this is a double-effect cycle $\mathrm{LiBr}+$ absorption machine with $174 \mathrm{~kW}$ and a theoretical COP of 1.34, which transforms the thermal energy (hot water at $140-170{ }^{\circ} \mathrm{C}$ ) coming from the Fresnel solar field or the PCM storage tank, into cold water to be used by the ESI of Seville Bermejo et al. (2010). Apart from the hot water, a cooling fluid for the condenser is needed in the absorption machine. This is obtained from the water catchment of the Guadalquivir river.

Solar Field: the solar field consists of a set of Fresnel solar collectors (see Figure 2) which concentrate solar radiation onto a line where a $64 \mathrm{~m}$ long absorption tube is located. The energy is transferred to a heat transfer fluid (in this case, pressurized water).

PCM storage tank: the PCM storage is a 18 metre long shell-tube heat exchanger with a 1.31 metre diameter (Figure 3). It consists of a series of tubes containing a heat transfer fluid and PCM fills in the space between the tubes and the shell.

The storage tank uses a hydroquinone as a PCM because the melting temperature is about $170{ }^{\circ} \mathrm{C}$, which is suitable for the water absorption chiller operational range $\left(145-170^{\circ} \mathrm{C}\right)$.

\section{Mathematical modeling of the Fresnel collector field}

In this section, the mathematical model of the solar collector field is presented. The equations governing the 


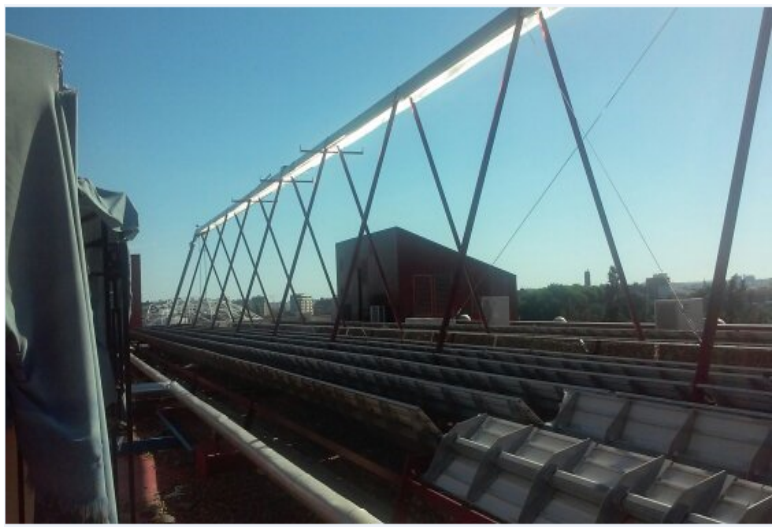

Figure 2: Fresnel collector field

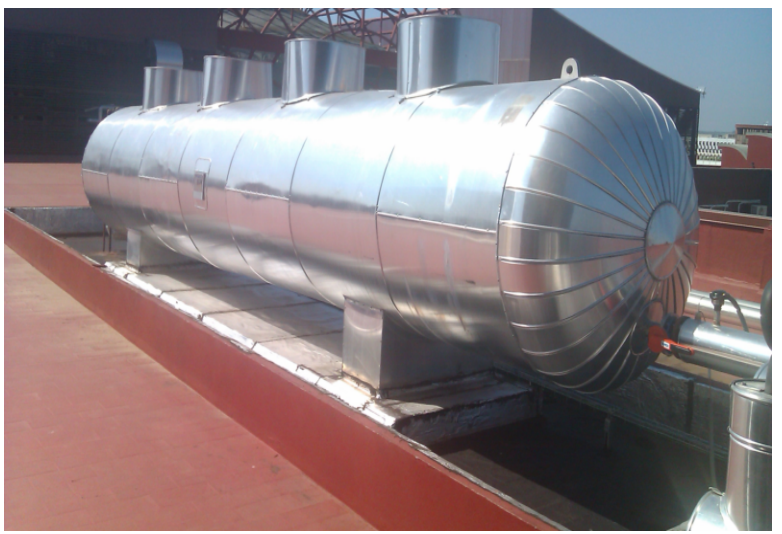

Figure 3: PCM storage tank

system dynamics are similar to those used in the case of the parabolic trough fields (Carmona (1985)). The difference relies on the computation of the geometrical efficiency and the shade factor. In (Pino et al. (2013)), the experimental validation of an optical and thermal model of the Fresnel collector was carried out in steady state.

There are two ways of modeling this kind of system: the concentrated parameter model and the distributed parameter model (Berenguel (1996)). In this paper, the distributed parameter model is used for simulation purposes and the concentrated parameter model is used for obtaining a feedforward controller.

It is worth pointing out that the equations used for this plant are the same as those used for modeling the parabolic trough solar plant. The difference depends on the way in which the model parameters are computed: the fluid characteristics (density, specific heat,

\begin{tabular}{|c|c|c|}
\hline Symbol & description & Units \\
\hline $\mathrm{t}$ & Time & $\mathrm{s}$ \\
\hline $\mathrm{x}$ & Space & $\mathrm{m}$ \\
\hline$\rho(t)$ & Density & $\mathrm{kgm}^{-3}$ \\
\hline $\mathrm{C}(\mathrm{t})$ & Specific heat capacity & $J K^{-1} k^{-1}$ \\
\hline$A$ & Cross sectional area & $m^{2}$ \\
\hline$T(x, t)$ & Temperature & $\mathrm{K},{ }^{\circ} \mathrm{C}$ \\
\hline$q(t)$ & water flow rate & $m^{3} s^{-1}$ \\
\hline$I(t)$ & Solar radiation & $W m^{-2}$ \\
\hline$n o(t)$ & geometric efficiency & Unitless \\
\hline$K_{o p t}$ & Optical efficiency & Unitless \\
\hline$G$ & Collector aperture & $\mathrm{m}$ \\
\hline$T_{a}(t)$ & Ambient temperature & $\mathrm{K},{ }^{\circ} \mathrm{C}$ \\
\hline$H_{l}(t)$ & $\begin{array}{l}\text { Global coefficient of } \\
\text { thermal loss }\end{array}$ & $W m^{-2 \circ} \mathrm{C}^{-1}$ \\
\hline$H_{v}(t)$ & $\begin{array}{l}\text { Temperature-dependent } \\
\text { part of the heat transmis- } \\
\text { sion coefficient }\end{array}$ & $W m^{-5} s^{\circ} \mathrm{C}^{-1}$ \\
\hline$H_{t}(t)$ & $\begin{array}{l}\text { Coefficient of heat trans- } \\
\text { mission metal-fluid }\end{array}$ & $W m^{-2 \circ} \mathrm{C}^{-1}$ \\
\hline$L$ & Length of pipe line & $\mathrm{m}$ \\
\hline
\end{tabular}

Table 2: Parameters description

metal-fluid heat transmission coefficient...), the thermal loss coefficient, the geometric properties of the solar field and the computation of the geometric efficiency which is more complicated than the case of the parabolic trough plant, as explained in Robledo et al. (2010).

\subsection{Distributed parameter model}

As described in section 2, the Fresnel solar collector field consists of a set of Fresnel solar collectors which concentrate solar radiation onto a line where a $64 \mathrm{~m}$ long absorption tube is located. The model is described by the following system of partial differential equations (PDE) describing the energy balance (Spoladore et al. (2011)):

$$
\begin{gathered}
\rho_{m} C_{m} A_{m} \frac{\partial T_{m}}{\partial t}=I K_{o p t} n o G-H_{l} G\left(T_{m}-T_{a}\right)-L H_{t}\left(T_{m}-T_{f}\right) \\
\rho_{f} C_{f} A_{f} \frac{\partial T_{f}}{\partial t}+\rho_{f} C_{f} q \frac{\partial T_{f}}{\partial x}=L H_{t}\left(T_{m}-T_{f}\right)
\end{gathered}
$$

where $m$ subindex refers to metal and $f$ subindex refers to a fluid. In Table 2, parameters and their units are shown.

The PDE system is solved by dividing the metal and fluid into $641 \mathrm{~m}$ long segments. The integration step is 
chosen to be 0.5 seconds. The computation of the geometric efficiency, which takes into account the effect of the cosine of the incidence angle of the solar beam and the shade factor, involves complex trigonometric formulas. These are well explained in Robledo et al. (2010).

Some parameters have been better adjusted than those presented in (Spoladore et al. (2011)). In particular, the density, specific heat and coefficient of heat transmission have been obtained as polynomial functions of the segment temperature and water flow using thermodynamical data of pressurized water. The coefficient of thermal losses has been obtained using real data from the Fresnel solar field. Their expression are as follows:

$$
\begin{gathered}
\rho_{f}=-0.0025 T_{f}^{2}-0.203 T_{f}+1003.91 \\
C f=5.16 e-7 T_{f}^{4}-1.56 e-4 T_{f}^{3}+0.0277 T_{f}^{2} \\
-1.627 T_{f}+4207.403 \\
H_{v}=1.34 e-4 T_{f}^{4}-7.78 e-2 T_{f}^{3}+18.73 T_{f}^{2} \\
-2.57 e 3 T_{f}+4.11 e 5
\end{gathered}
$$$$
H_{t}=H_{v} q^{0.8}
$$

The thermal loss coefficient can be calculated using equation (5):

$$
H_{l}=(0.00122)\left(T_{m}-T_{a}\right)+0.001763
$$

In order to adjust the model parameters, a set of 10 days covering different operating conditions has been used. The following two days have not been used for identification but for validation of the model behavior.

Figure 4 corresponds to a typical summer day. The oscillations in the inlet temperature are produced by the temperature returning from the chiller. Figure 5 shows the evolution of the error between the distributed parameter model and the real data. A maximum error of 2.5 ${ }^{\circ} \mathrm{C}(1.6 \%)$ can be observed.

Figure 6 corresponds to a day when the solar collector field is working in recirculation mode. This operation mode is used to heat up the solar field. Figure 7 shows the evolution of the error between the distributed parameter model and the real data throughout the day. At $14.6 \mathrm{~h}$, a part of the solar field $(70 \%)$ is defocused. A maximum error of $1.6{ }^{\circ} \mathrm{C}$ (about $2 \%$ ) can be observed.
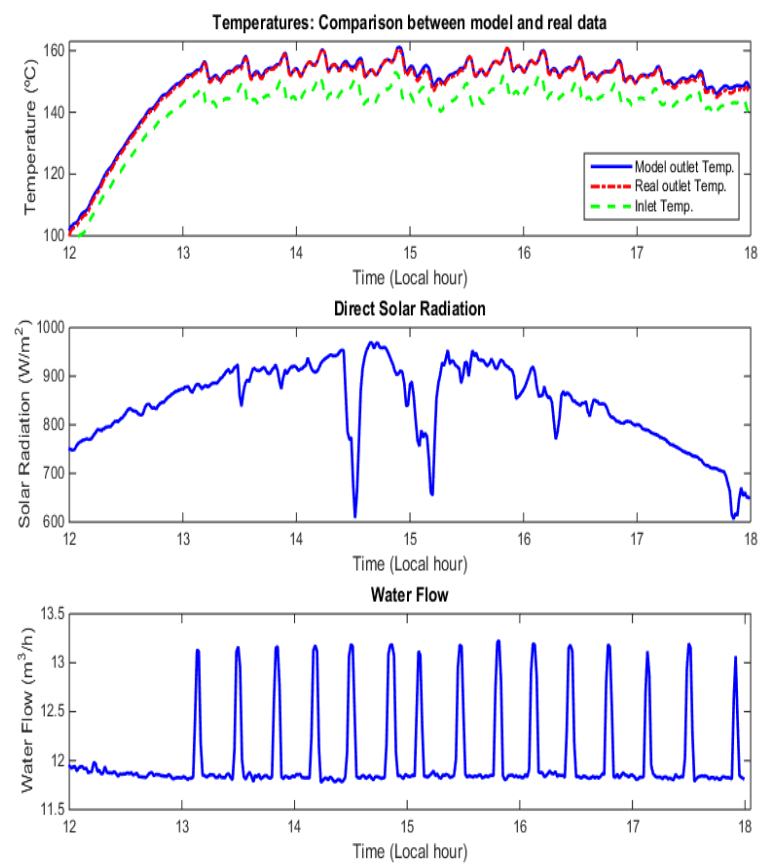

Figure 4: Solar field evolution Model vs Real: 29/06/2009

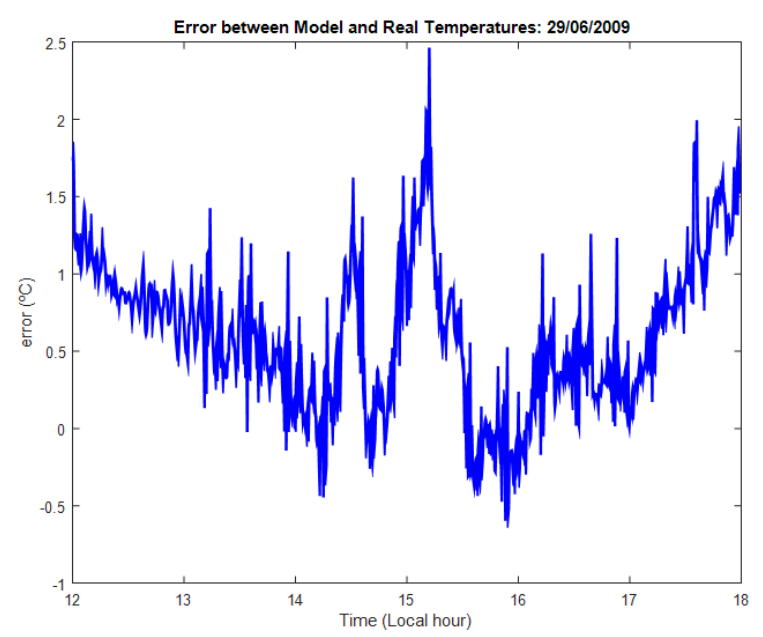

Figure 5: Errors between distributed parameter model and real data: 29/06/2009 

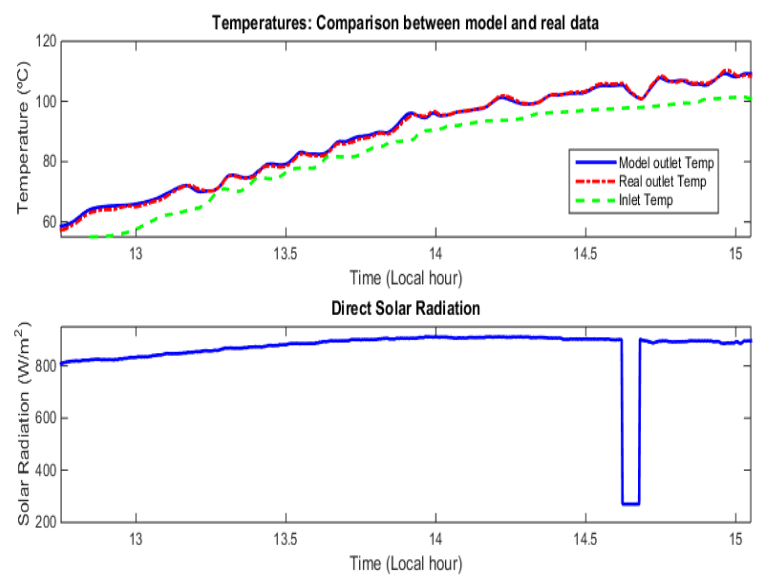

Water Flow

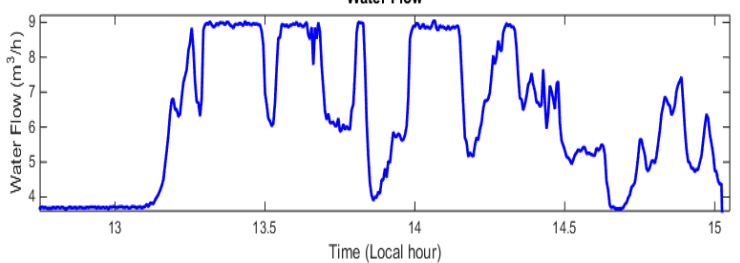

Figure 6: Solar field evolution Model vs Real: 31/07/2017

\subsection{Concentrated parameter model}

The concentrated parameter model provides a lumped description of the whole field. The variation in the internal energy of the fluid can be described by the equation (Robledo et al. (2010):

$$
C \frac{d T_{\text {out }}}{d t}=K_{\text {opt }} n o S I-q P c_{p}\left(T_{\text {out }}-T_{\text {in }}\right)-H_{l} S\left(\bar{T}-T_{a}\right)
$$

where $q$ is the water flow, $T_{\text {out }}$ and $T_{\text {in }}$ are the outlet and inlet oil temperatures, respectively, $\bar{T}$ is the mean value between inlet and outlet temperatures and $T_{a}$ is the ambient temperature. $C$ is the thermal capacity of the solar field, $K_{o p t}$ is the optical efficiency (which incorporates the effects of mirror reflectivity, tube absorptance, interception factor), $I$ is the solar irradiance and $S$ is the total reflective surface measuring $352 \mathrm{~m}^{2}$. The geometric efficiency no is a function of the cosine of the incidence angle between the mirrors' normal vector and the solar beam and the shade factor, $P c_{p}$ takes into account some geometrical and thermal properties of the loop and $H_{l}$ is the coefficient of thermal losses.

Figure 8 shows a comparison between the evolution of the distributed parameter model, the concentrated parameter model and the real data. Although the evolution of the concentrated parameter model is close to the real one, the distributed parameter model achieves a more accurate response as expected. Figure 9 depicts the evolution of the error for the two considered models.

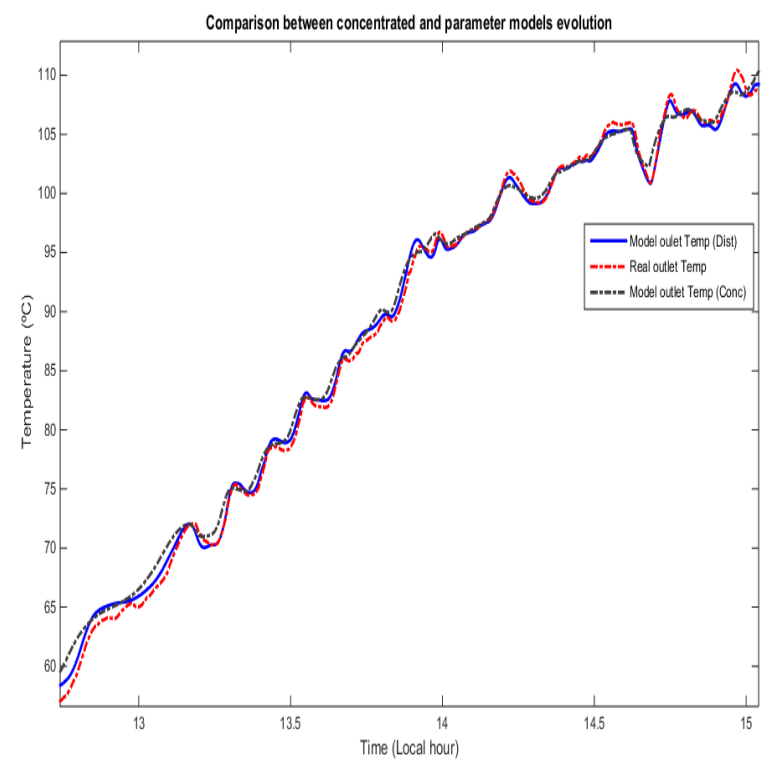

Figure 8: Solar field evolution Distributed Model vs Real vs Concentrated Model: 31/07/2017 


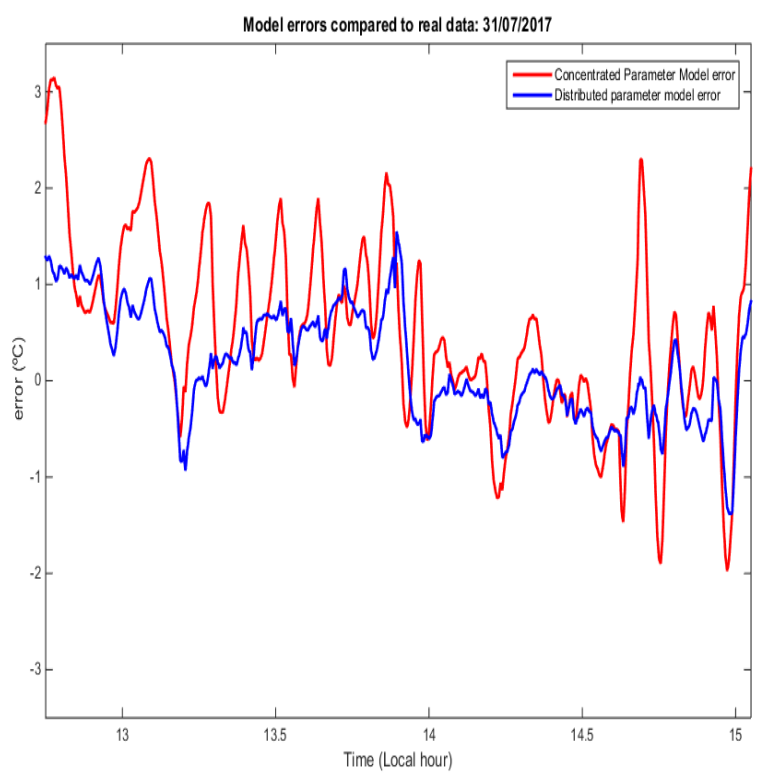

Figure 9: Error Comparison: 31/07/2017

In this paper, the concentrated parameter model is used to implement a feedforward controller.

\section{Gain Scheduling Generalized Model Predictive Control Strategy}

In this section, the proposed model predictive control strategy is presented.

\subsection{MPC control scheme}

Since the dynamics of the solar collector field is highly nonlinear a feedforward in series with the plant is used. The feedforward controller has a twofold objective: on one hand, the feedforward controller has demonstrated to be very useful in rejecting the multiple disturbance sources which affect a solar collector field (Camacho et al. (1992)). On the other hand, a series feedforward linearizes approximately the highly nonlinear response of the solar field as explained in $\mathrm{Ca}$ macho et al. (1997). In fact, this approach is simple and provides results comparable to the use of feedback linearization (Cirre et al. (2007)), with lower complexity. The linear model to be used in the control strategy corresponds to the set feedforward+plant.

The control strategy works as follows: The model predictive control receives the desired outlet temperature set-point and the current outlet temperature of the solar field. It computes a virtual reference temperature
Tre $f_{\text {vir }}$ given to the feedforward controller. The feedforward controller, using the data from the solar field, computes the water flow to reach the desired set-point. For the MPC controller, the set feedforward+plant behaves as a linear model with an approximate unitary gain.

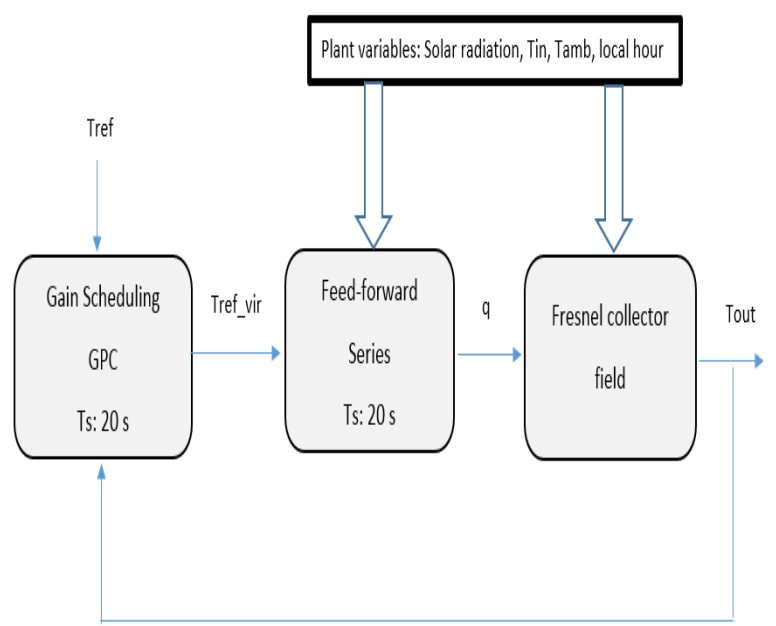

Figure 10: Control Scheme

The feedforward is computed using the concentrated parameter model as follows:

$$
q=\frac{\left(K_{o p t} n o S I-H_{l} S\left(\bar{T}-T_{a}\right)\right)}{q P c_{p}\left(T r e f_{v i r}-T_{i n}\right)}
$$

It is worth noting that, if the model is perfect, Tre $f_{\text {vir }}$ will be equal to $T_{r e f}$ in steady state. However, because the model is, in general, not perfect, these two values will not be equal. The GS-GPC controller computes Tre $f_{\text {vir }}$ so that the outlet temperature of the solar field tracks the desired reference.

Another point to be considered is that, although a series feedforward compensation is used, the plant dynamics change substantially with the water flow level. In particular, this kind of system is difficult to control at low flow level. If the control strategy uses only a particular linear model associated to a flow level to predict the system evolution, when the plant works at a different flow level, the dynamics will change and the performance of the controller may be deteriorated. In order to deal with this problem, a gain scheduling approach is used in this paper.

\subsection{MPC problem formulation}

MPC control algorithms consist of the following 3 steps (Camacho and Bordons (2004), Rawlings and Mayne (2009)): 
(i) Use a model to predict the process evolution at future time instants (horizon), depending on a control sequence.

(ii) Compute the control sequence which minimizes a certain objective function.

(iii) Apply only the first element of the control sequence, then recalculate the sequence shifting the horizon one step in the future (receding horizon).

The model used to predict the process evolution can be either linear or nonlinear. The model used to predict the future evolution of the plant is considered to be a discrete-time transfer function. The model predictive control strategy, in this case, is called generalized predictive controller (GPC) (Clarke et al. (1987a); Clarke et al. (1987b): Beschi et al. (2013)).

In general, the mathematical expression of the MPC problem can be posed as follows:

$$
\begin{aligned}
\min _{\Delta u} J=\sum_{t=1}^{N_{p}}\left(y_{k+t \mid k}-y_{k+t}^{r e f}\right)^{\top}\left(y_{k+t \mid k}-y_{k+t}^{r e f}\right) \\
+\lambda \sum_{t=0}^{N_{c}-1} \Delta u_{k+t \mid k}^{\top} \Delta u_{k+t \mid k}
\end{aligned}
$$

s.t.

$$
\begin{aligned}
y_{k+t \mid k} & =f\left(\Delta u, y_{k+t-1}, y_{k+t-2}, \ldots\right) \\
u_{k+t} & =u_{k+t-1}+\Delta u_{k+t} \\
u_{\min } & \leq u_{k+t} \leq u_{\max } \\
t & =0, \ldots, N_{p}-1
\end{aligned}
$$

where $N_{p}$ and $N_{c}$ stand for the prediction and the control horizons respectively. The parameter $\lambda$ penalizes the control effort. $\Delta u$ is the vector of future control moves $\left(\Delta u=\left[\Delta u_{k}, \Delta u_{k+1} \cdots \Delta u_{k+N_{c}-1}\right]\right)$. For the Fresnel solar collector field, the variable $y_{k+t \mid k}$ is the prediction of the system temperature at instant $k+t$ based on the available information at instant $k$ and using the linear model (see subsection 4.3). The variable $y_{\text {ref }}$ is the desired reference temperature for the outlet temperature. The control signal $u_{k}$ is the virtual temperature reference Tre $f_{\text {vir }}$ provided to the feedforward by the GPC algorithm.

In this case, only the following constraints in the amplitude of the signal $u$ are considered:

$$
T_{\text {in }} \leq u_{k+t \mid k} \leq 225
$$

This range is chosen because the solar field cannot work above $225^{\circ} \mathrm{C}$ and working in a temperature below the inlet temperature is not of interest.

To ensure that the water flow is confined to the desired values, it is saturated.

\subsection{Gain Scheduling approach}

A gain scheduling controller is an easy way to cope with the changing dynamics of a nonlinear system. Since a linear controller is tuned to a particular working point, when the plant evolves far from the design conditions, the linear controller performance may deteriorate. A simple solution would be to design a set of controllers covering the different operating conditions and switching smoothly among them (Leith and Leithead (2000)). In this case, the parameters of the linear model used to predict the future evolution of the plant change with respect to the water flow.

This approach is similar to that proposed in Camacho et al. (1994): four water flow levels are considered covering the entire range of operation $\left(3.8-9.1 \mathrm{~m}^{3} / h\right)$. In Camacho et al. (1994), the unconstrained GPC problem is solved for four flow levels and four gains are obtained. The controller gain is interpolated between the intermediate values. In the approach used here, the linear model parameters are interpolated for intermediate flow values and, then, the GPC problem is solved.

The discrete-time transfer functions have been chosen as indicated in equation (9):

$$
G\left(z^{-1}\right)=\frac{b_{o}+b_{1} z^{-1}+b_{2} z^{-2}+b_{3} z^{-3}+b_{4} z^{-4}}{1+a_{o} z^{-1}+a_{1} z^{-2}}
$$

The high order of the numerator aims at modeling high frequency dynamics (Pickhardt (2000)). The sampling time for the MPC control strategy has been chosen as 20 seconds. This choice is suitable for grasping the fundamental dynamics of the plant (time constants between 140 and 350 seconds) and, at the same time, for keeping the real part of the poles of the discretized system reasonably smaller than 1 (Aström and Wittenmark (1997)). The time constants are estimated for different flow conditions using a step in the input of the extended plant (feedforward and plant). That is, a step in the temperature reference Tre $_{\text {vir }}$ to the series feedforward in steady state.

To identify the linear model parameters, a PRBS signal is applied to the distributed parameter model in series with the feedforward and then, using a least square identification method to obtain those parameters. Figure 11 shows the step response for the discrete transfer functions associated to four water flow conditions. As can be seen, the system response becomes substantially slower at low flow levels.

Table 4.3 shows the parameter of linear models for the considered water flow conditions.

Let $A_{i}\left(z^{-1}\right)=\left[\begin{array}{lll}1 & a_{o} z^{-1} & a_{1} z^{-2}\end{array}\right]$ and $B_{i}\left(z^{-1}\right)=$ $\left[b_{o} b_{1} z^{-1} b_{2} z^{-2} b_{3} z^{-3} b_{4} z^{-4} b_{5} z^{-5}\right]$, the parameters for 


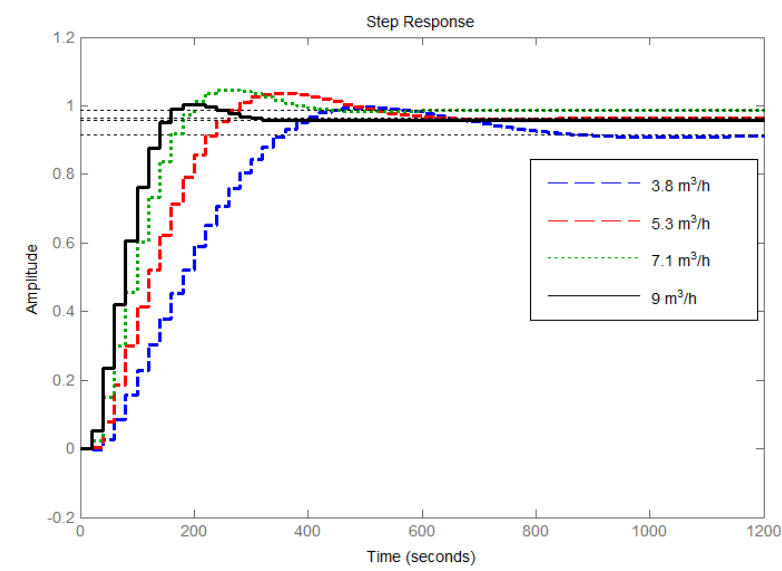

Figure 11: Linear models step response for different water flow conditions

\begin{tabular}{|l|c|c|c|l|}
\hline$q$ & 3.8 & 5.3 & 7.1 & 9.1 \\
\hline$b_{o}$ & $-4.688 \mathrm{e}-5$ & $-6.308 \mathrm{e}-5$ & $-1 \mathrm{e}-4$ & $-2.1 \mathrm{e}-4$ \\
$b_{1}$ & $-2.683 \mathrm{e}-3$ & $3.484 \mathrm{e}-3$ & $2.241 \mathrm{e}-2$ & $5.419 \mathrm{e}-2$ \\
$b_{2}$ & $3.280 \mathrm{e}-2$ & $6.813 \mathrm{e}-2$ & $9.436 \mathrm{e}-2$ & 0.108 \\
$b_{3}$ & $9.711 \mathrm{e}-3$ & $-1.847 \mathrm{e}-2$ & $-3.815 \mathrm{e}-2$ & $-2.856 \mathrm{e}-2$ \\
$b_{4}$ & $-1.983 \mathrm{e}-2$ & $-1.163 \mathrm{e}-2$ & $9.231 \mathrm{e}-3$ & $2.838 \mathrm{e}-2$ \\
$a_{o}$ & -1.802 & -1.704 & -1.547 & 1.349 \\
$a_{1}$ & 0.824 & 0.748 & 0.638 & 0.517 \\
\hline
\end{tabular}

Table 3: Linear model parameters depending on the water flow $(q)$ $\left(m^{3} / h\right)$

the linear model associated to the 4 water flow considered $(i=1,2,3,4)$, where $q_{1}=3.8 \mathrm{~m}^{3} / \mathrm{h}, q_{2}=5.3 \mathrm{~m}^{3} / \mathrm{h}$, $q_{3}=7.1 \mathrm{~m}^{3} / \mathrm{h}, q_{4}=9.1 \mathrm{~m}^{3} / \mathrm{h}$. To compute the parameters of the linear model for a particular flow level $q$ :

$$
\begin{gathered}
\text { if } q<q_{1} \text { then } \\
A\left(z^{-1}\right)=A_{1}\left(z^{-1}\right) \\
B\left(z^{-1}\right)=B_{1}\left(z^{-1}\right) \\
\text { if } q>q_{4} \text { then } \\
A\left(z^{-1}\right)=A_{4}\left(z^{-1}\right) \\
B\left(z^{-1}\right)=B_{4}\left(z^{-1}\right) \\
i f q_{i} \leq q \leq q_{i+1}, \text { for } i=1,2,3 \text { then } \\
\frac{q-q_{i}}{q_{i+1}-q_{i}} A_{i}\left(z^{-1}\right)+\frac{q_{i+1}-q}{q_{i+1}-q_{i}} A_{i+1}\left(z^{-1}\right) \\
B\left(z^{-1}\right)=\frac{q-q_{i}}{q_{i+1}-q_{i}} B_{i}\left(z^{-1}\right)+\frac{q_{i+1}-q}{q_{i+1}-q_{i}} B_{i+1}\left(z^{-1}\right)
\end{gathered}
$$

\section{Simulation results}

In this section, three simulations are carried out to demonstrate the performance of the proposed control strategy. In the first one, a comparison between the proposed way of implementing the GS-GPC approach is compared to the one proposed in Camacho et al. (1994), for the unconstrained case. Then, two simulations where the GS-GPC controller is compared to a generalized model predictive controller designed for medium flow conditions (MF-GPC). The design point was chosen as $6.5 \mathrm{~m}^{3} / \mathrm{h}$. The GPC parameters have been chosen as $N_{c}=7, N_{p}=12$ and $\lambda=6$ for both strategies. The water flow constraints are considered to be $2.7-10 \mathrm{~m}^{3} / \mathrm{h}$ for simulation purposes. The MPC problem is solved by using the quadratic optimization function provided in the Matlab optimization toolbox.

In the first place, the advantage of interpolating the linear model parameter and solving the unconstrained GPC problem (henceforth Approach I) compared to the approach used in Camacho et al. (1994) (Approach II) is explained. Figure 12 shows the temperature evolution for the two control approaches on a clear day. As seen in figure 12, the Approach II performance is quite close to that obtained with Approach I although this one performs slightly better. Table 4 provides the ITAE (Integral of Time multiplied by Absolute Error) and the ISE (Integral of Square errors) for this simulation.

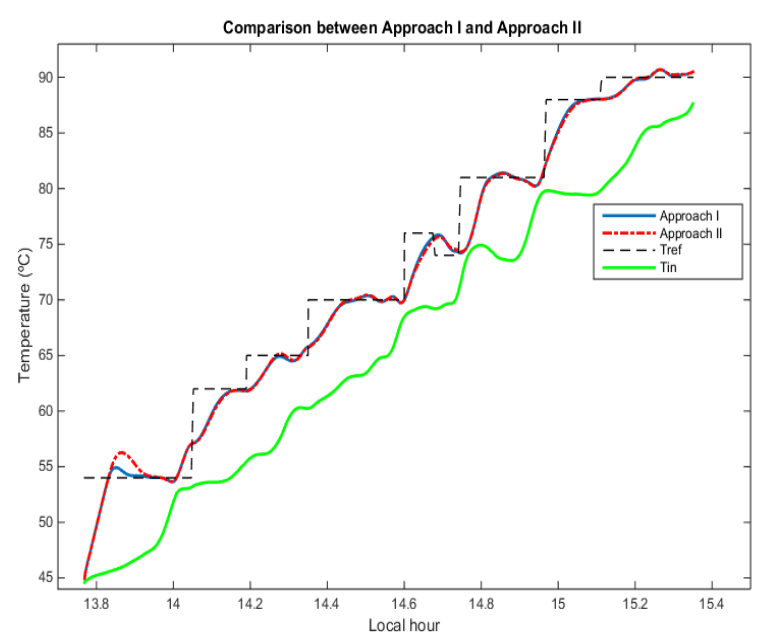

Figure 12: Comparison between the performance of Approach I and the performance of Approach II.

Figure 13 shows the comparison of the evolution of three controller parameters: the real optimal value obtained for the linear model associated to a particular water flow level, the value obtained by Approach I and the 


\begin{tabular}{cccc}
\hline ITAE Criterion & Approach I & Approach II & diff(\%) \\
& 14613.3 & 15656.8 & 7.13 \\
ISE Criterion & Approach I & Approach II & diff(\%) \\
& 9988.8 & 10191.1 & 2.01 \\
\hline
\end{tabular}

Table 4: Performance comparison using ITAE and ISE criteria for the comparison between the Approach I and the Approach II.

value obtained by Approach II. As seen, the evolution obtained with Approach I is closer to the optimal one, particularly at low flow levels. The Approach II evolution is a good approximation at medium-high flow levels.
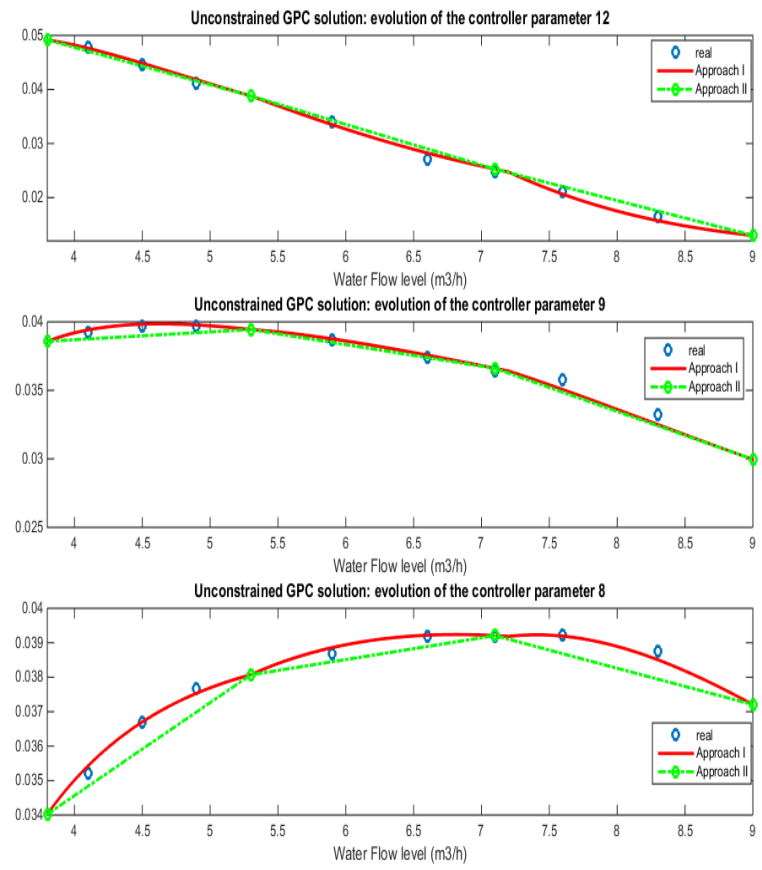

Figure 13: Comparison between the evolution of the three controller parameters: real, Approach I and Approach II.

Figure 14 shows the second simulation consisting of a series of increasing steps in the temperature reference. As can be seen, when the water flow is around the design point, the MF-GPC performance is very similar to that obtained with the GS-GPC. As the water flow decreases to low values, the performance of the MF-GPC deteriorates and overshoots appear. This can be observed when working at low water flow. From $13.2 \mathrm{~h}$ onwards, several disturbances affect the solar field. The first one is a step in the inlet temperature which goes from $105{ }^{\circ} \mathrm{C}$ to $109{ }^{\circ} \mathrm{C}$. The GS-GPC better rejects the disturbance than the MF-GPC. Two solar radiation disturbances are simulated at 13.8 and $14.6 \mathrm{~h}$. As can be seen, the GS-GPC recovers the temperature and leads it around the desired set-point with small oscillations. The MF-GPC overshoot is far higher than that obtained with the GS-GPC. The GS-GPC is more aggressive with the control signal but it is needed to properly reject the disturbances.
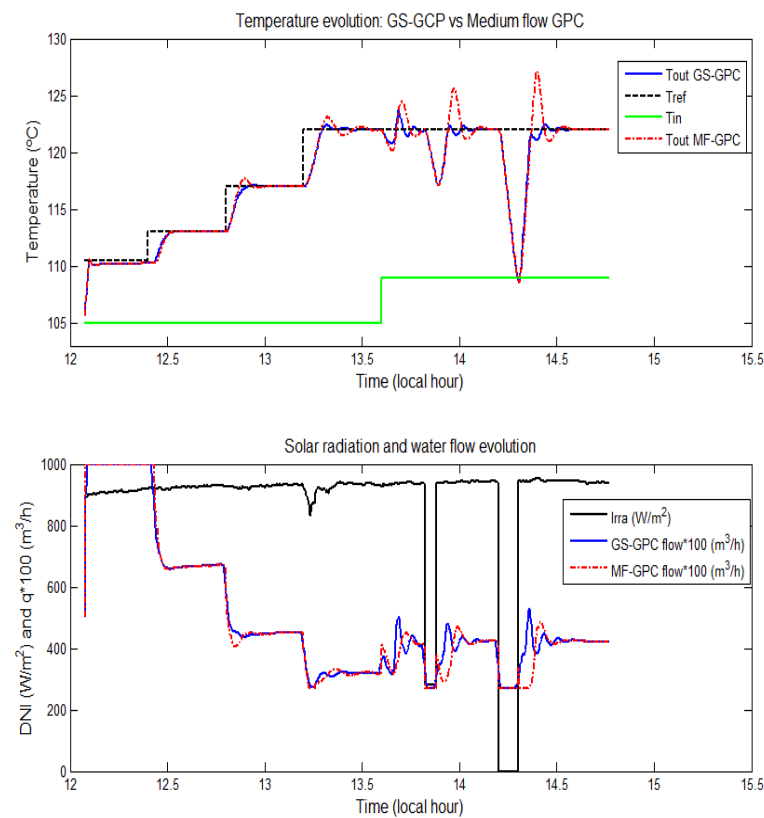

Figure 14: Simulation 2: Comparison between GS-GPC and MF-GPC

Figure 15 shows the third simulation. The inlet temperature and the solar radiation data have been taken from the real solar field corresponding to 31/07/2017. The steps in the inlet temperature are produced because the solar field was working in recirculation mode. In this mode, the heated water is recirculated and reaches the input of the solar field after passing through a long pipe. This kind of disturbance is difficult to deal with. If the controller is not properly tuned, oscillations are produced in the outlet temperature, these oscillations propagate to the input of the solar field later producing more oscillations. Furthermore, the inlet temperature disturbance delay depends on the water flow. Taking anticipated actions to reject the inlet temperature disturbance is not an easy matter.

The simulation consists of a series of increasing setpoints for the outlet temperature. As can be seen, similar conclusions as those obtained in simulation 1 can be drawn. The GS-GPC works well in all water flow conditions with very small overshoots (less than $1^{\circ} \mathrm{C}$ ) and its performance is better than that obtained with the MF-GPC. Figure 16 shows the flow levels for both con- 
trollers.

As a general comment, it can be seen that when the flow level is far from the design point of the MF-GPC the performance deteriorates, whereas the performance of the GS-GPC remains appropriate. This is due to the gain scheduling compensation that changes the linear model parameters with the flow level. The difference is especially notorious at low flow levels.

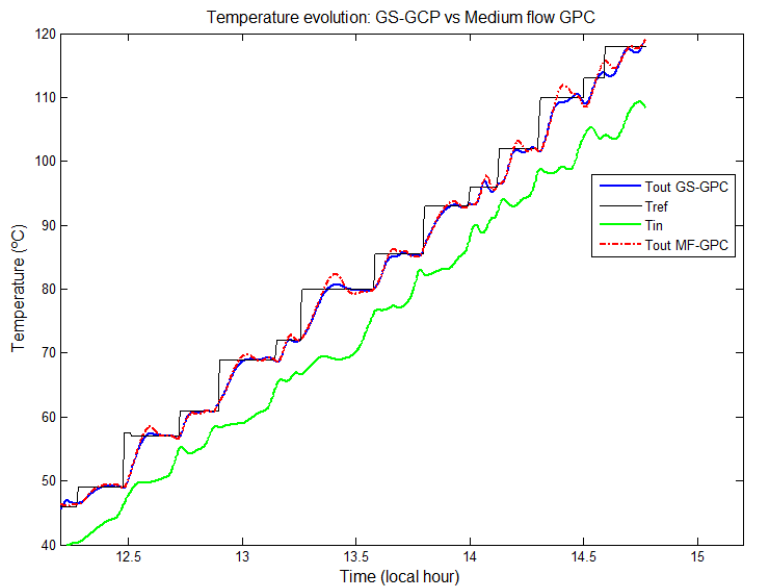

Figure 15: Simulation 3:Comparison of temperature evolution between GS-GPC and MF-GPC

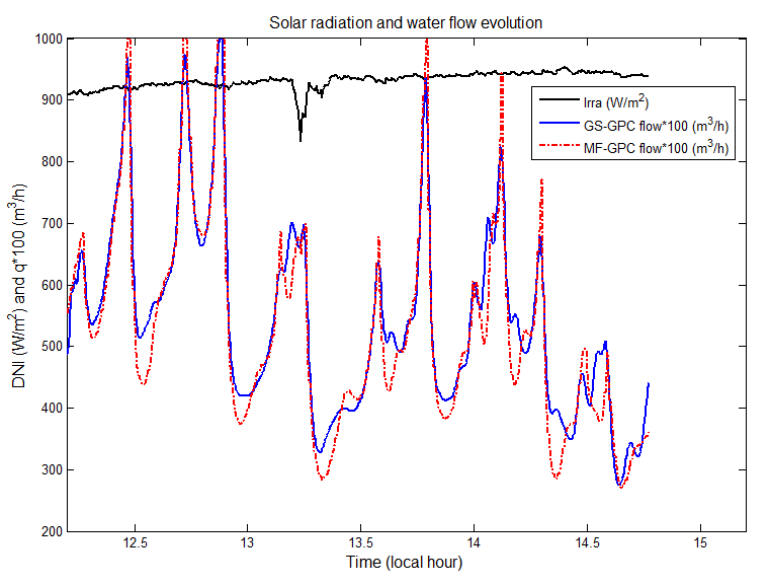

Figure 16: Simulation 2: Water flow levels and solar radiation

Finally, Table 5 provides the ITAE criterion and the ISE criterion for the two controllers in the simulations shown in this section. As expected, the GS-GPC achieves the best performance criterion in both cases.

\begin{tabular}{cccc}
\hline ITAE Criterion & GS-GPC & MF-GPC & $\operatorname{diff}(\%)$ \\
Sim 2 & 17856.9 & 22219.4 & 24.43 \\
Sim 3 & 5148.3 & 5882.1 & 14.25 \\
ISE Criterion & GS-GPC & MF-GPC & $\operatorname{diff}(\%)$ \\
Sim 2 & 35279.1 & 36861.4 & 4.483 \\
Sim 3 & 12230.1 & 12486.4 & 2.08 \\
\hline
\end{tabular}

Table 5: Performance comparison using ITAE and ISE criteria

\section{Real Tests}

In this section, two real tests carried out at the Fresnel collector field are presented. These tests were carried out on 06/10/2017 and 09/10/2017.

Both experiments were done in recirculation mode and the variable frequency drive of the water pump was limited to the 40-100\% range which corresponds to a flow range between 3.7 and $9.1 \mathrm{~m}^{3} / \mathrm{h}$.

Another important point concerns the optical efficiency. Several studies determined that the overall optical efficiency of the solar field is about 0.22 . However, due to some miscalibrated mirrors, efficiency at the beginning and at the end of the operation was found to be substantially lower. This can be observed in the tests, because the thermal jump obtained at the beginning of the day was significantly smaller than those obtained in the middle of the day for similar water flow levels.

In order to estimate this effect, a lumped parameter model is used. The parameter is called $\eta_{c a l}$ and it represents the efficiency loss due to the miscalibration.

$C \frac{d T_{\text {out }}}{d t}=\eta_{\text {cal }} K_{\text {opt }} n o S I-q P c_{p}\left(T_{\text {out }}-T_{\text {in }}\right)-H_{l} S\left(\bar{T}-T_{a}\right)$

From equation (10), the parameter can be computed iteratively throughout the test as follows:

$$
\eta_{\text {cal }}=\frac{C \frac{d T_{\text {out }}}{d t}+H_{l} S\left(\bar{T}-T_{a}+q P c_{p}\left(T_{\text {out }}-T_{\text {in }}(t-k)\right)\right.}{K_{\text {opt }} n o S I}
$$

The previous expression can only be computed when solar radiation is higher than 0 . Since this expression uses the derivative of the outlet temperature, the evolution of the estimated parameter $\eta_{c a l}$ has to be filtered in order to avoid abrupt changes.

As far as the intlet temperature is concerned, the lumped parameter model most used in literature does not consider the delay between the inlet temperature and the outlet temperature. This is done because the lumped parameter model is a simplified description of the field, where the spatial distribution is not considered 
and the inlet oil temperature changed very slowly in the ACUREX field, as it came from a storage tank.

In this process, changes in the inlet water temperature can be fast and the transport delay from the input temperature to the output of the collectors has to be considered. The inlet temperature to be used in equation (11) is not that measured in the current sampling time, but that which is affecting the outlet temperature at that moment. In other words, time delay $k$ is the time taken by a change in the inlet temperature to be reflected in the outlet temperature and has been estimated as a function of the water flow. Figure 17] shows the time delay versus the water flow. These measurements were taken from the real Fresnel collector field, as in (Cirre et al.(2007)). In order to obtain this relationship, the solar Fresnel collector field worked in recirculation mode. For five flow levels, the time taken for a variation in the inlet temperature to become visible in the outlet temperature is measured.

Another way to cope with this transport delay for this kind of system can be found in (Normey-Rico et al. (1998), using a discrete-time approximation of the equation which accounts for different values of the flow during different sampling intervals.

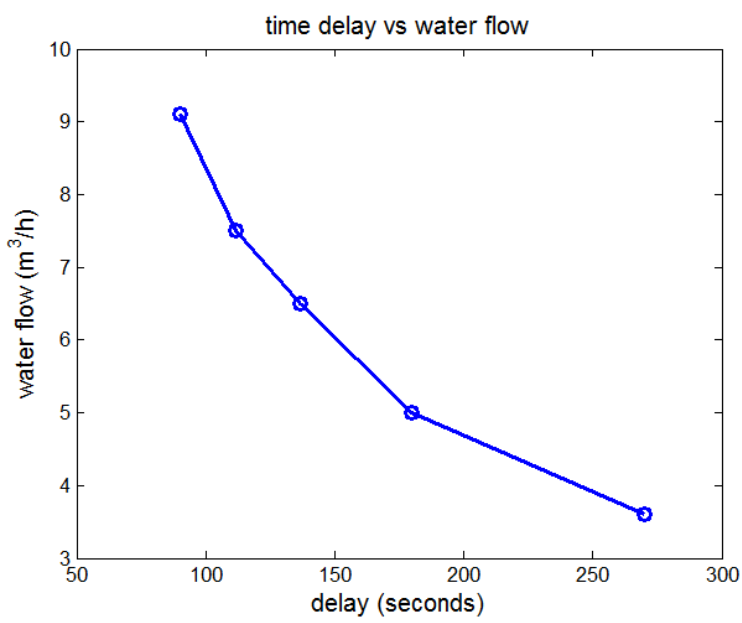

Figure 17: Time delay of the inlet temperature depending on the water flow

Figure 18 shows the test carried out on 06/10/2017. Throughout the test, the tuning parameters were chosen as $N_{c}=7, N_{p}=12$ and $\lambda=7$. Parameter $\lambda$ is chosen higher than that used in simulations in order to obtain less aggressive behavior and avoid stress to the pump. As can be seen, the controller tracks the desired setpoints properly with very small overshoots. The rise time is about 7-8 minutes. As the fluid is being recirculated through a pipe, the changes in the outlet tempera- ture affect the inlet temperature of the solar field. It can be observed that the inlet temperature disturbances are well dealt with by the GS-GPC controller.

In order to show the response of the controller when solar radiation disturbances occur, the solar field is defocused. At $15.02 \mathrm{~h}$, the solar field is completely defocused for 3 minutes and then is focused again. The controller had no information about this. As can be seen the outlet temperature rises very abruptly due to two effects: the focusing of all the mirrors and the rising inlet temperature. The GS-GPC controller manages to recover the temperature in spite of the strong disturbances and steers it around the set-point. At 15.26, $40 \%$ of the mirrors are defocused for 2 minutes. The GS-GPC controller is able to lead the outlet temperature around the set-point with an overshoot of $1.5^{\circ} \mathrm{C}$.
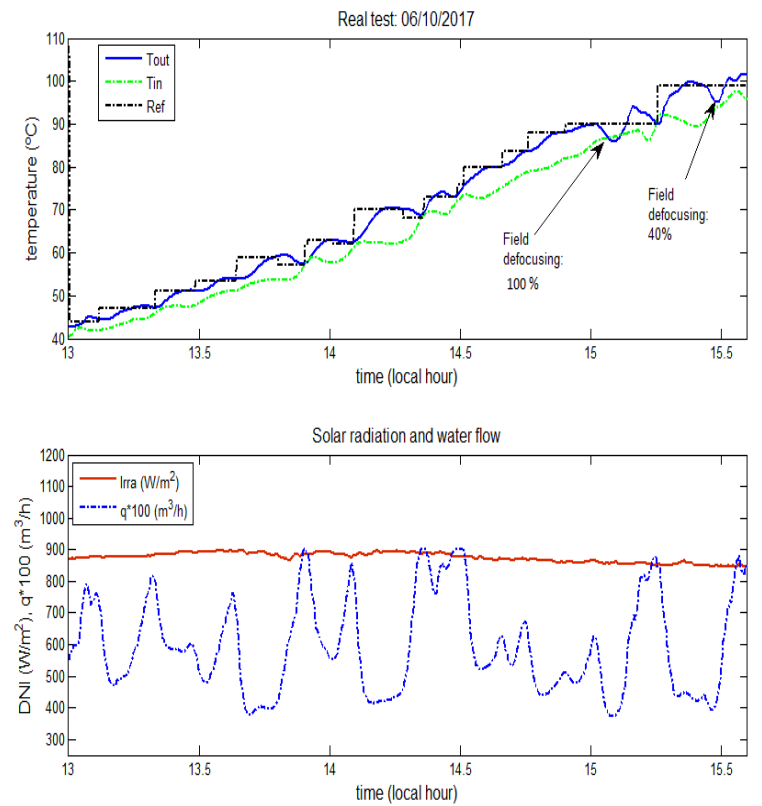

Figure 18: Real Test: 06/10/2017

The aforementioned effect of the miscalibrated mirrors can be observed in figure 19 . At the beginning of the operation, the efficiency loss parameter $\eta_{\text {cal }}$ is about 0.4. After some initial oscillations, the estimator converges to a value of approximately 0.45 . As time passes efficiency increases because the mirrors are better focused and more energy is collected by the fluid. It is interesting to note that this parameter also estimates the effect of defocusing the solar field acting as a disturbance observer. When the solar field is completely defocused at $15.2 \mathrm{~h}, \eta_{\text {cal }}$ falls and when it is focused again the parameter increases again because the efficiency is 
increased. Parameter $\eta_{\text {cal }}$ could be estimated using an observer or the Kalman filter (Karamali and Khodabandeh (2017)). In this paper, for simplicity, a simple low pass filter is used.

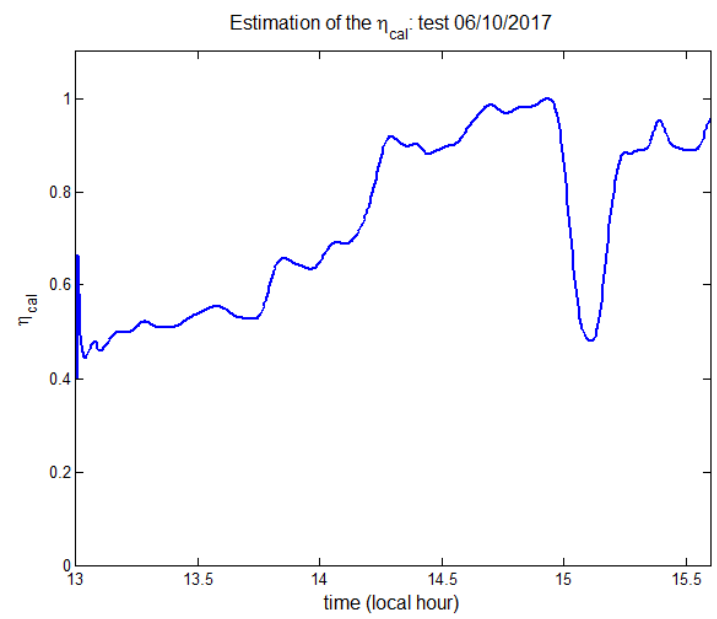

Figure 19: Estimation of $\eta_{c a l}$ throughout the real test:06/10/2017

Figure 20 shows the test performed on 09/10/2017. The test consisted of a series of changing set-points which were well tracked by the GS-GPC controller. The controller was able to cope with the inlet temperature changes. At $15.02 \mathrm{~h}, 40 \%$ of the mirrors were defocused to simulate a sudden fall of solar radiation. As seen, the controller diminished the water flow when the outlet temperature fell and when the field was again focused, it lead the temperature to the set-point with small oscillations. At 15.12, communication with the plant was lost and when recovered the set-point was $110{ }^{\circ} \mathrm{C}$ by default. It produced a drop in the water flow to $4 \mathrm{~m}^{3} / \mathrm{h}$. Then, the set-point was changed to $95{ }^{\circ} \mathrm{C}$ which the controller tracked after some oscillations produced by the drop in the water flow. At 15.8 the solar field was completely defocused for 5 minutes to simulate passing clouds. When the solar field was focused, the controller recovered the outlet temperature and tracked the set-point in spite of the strong disturbances.

Figure 21 shows the estimation of $\eta_{\text {cal }}$ throughout the test. The conclusions obtained are very similar to those obtained in the previous test. The parameter value at the beginning of the test is low, due to the miscalibrated mirrors. When the field is defocused, parameter $\eta_{\text {cal }}$ estimates this effect and helps the controller to act properly.

In conclusion, the proposed control strategy performs well in both tests, tracking the desired set-points when
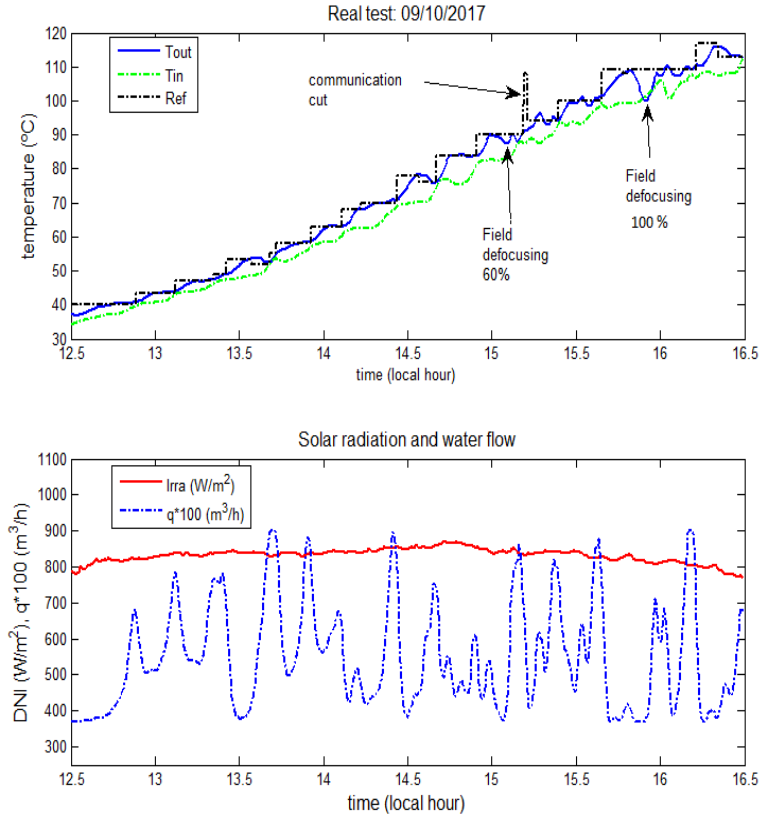

Figure 20: Real Test: 09/10/2017

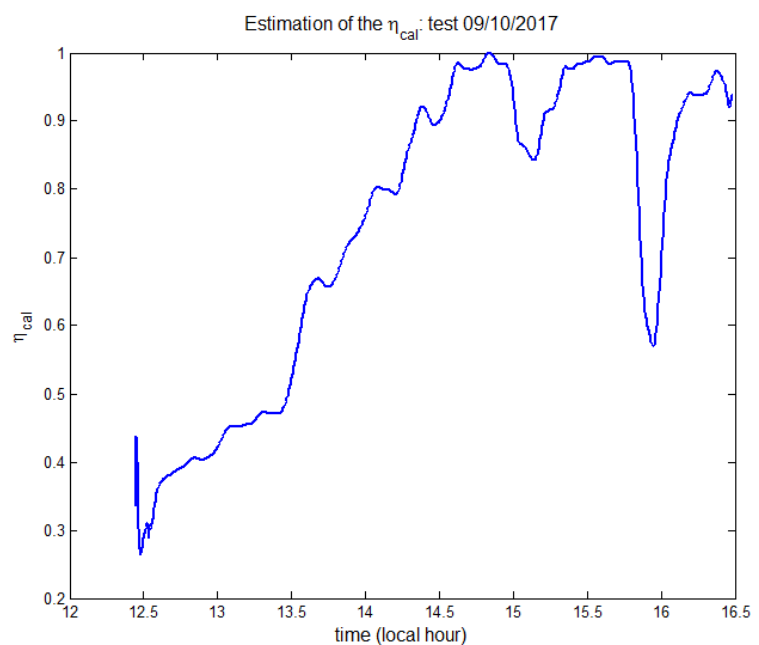

Figure 21: Estimation of $\eta_{\text {cal }}$ throughout the real test:09/10/2017 
possible in spite of strong disturbances.

\section{Conclusions}

Advanced control strategies can play an important role in improving the efficiency of solar plants. In particular, model predictive control strategies have been applied successfully when controlling solar plants.

In this paper, a gain scheduling model predictive control strategy is designed for the Fresnel collector field located at the Escuela Superior de Ingenieros de Sevilla. Simulation results were provided showing the effectiveness of the proposed strategy. Furthermore, two real tests are presented. These tests show that the proposed controller successfully tracks the desired set-points and efficiently rejects the multiple disturbances affecting the solar field.

\section{Acknowledgements}

The authors would like to acknowledge the European Reseacrh Council, the Spanish Ministry of Economy, Industry and Competitiveness and the UE ERDF for funding the work under the Advanced Grant OCONTSOLAR (Project ID: 789051), Control Predictivo de Microrredes Reconfigurables con Almacenamiento Híbrido y Móvil (DPI2016-78338-R) and ENERPRO (DPI2014-56364-C2-1-R). Likewise, we would like to thank Mario de la Rosa for his support and hard work on the plant tests.

\section{References}

Abengoa, 2017. Our plants.

URL http://www.abengoasolar.com/web/es/ plantas_solares/plantas_propias/sudafrica/

Andrade, G. A., Pagano, D. J., Álvarez, J. D., Berenguel, M., 2013. A practical NMPC with robustness of stability applied to distributed solar power plants. Solar Energy 92, 106-122.

Aström, K. J., Wittenmark, B., 1997. Computer-controlled systems: theory and design; 3rd ed. Prentice-Hall information and system sciences series. Prentice-Hall, Upper Saddle River, NJ.

Berenguel, M., 1996. Contributions to the control of distributed solar collectors. Ph.D. thesis, Universidad de Sevilla.

Berenguel, M., Cirre, C. M., Klempous, R., Maciejewski, H., Nikodem, M., Nikodem, J., Rudas, I., Valenzuela, L., 2005. Hierarchical control of a distributed solar collector field. Computer Aided Systems Theory EUROCAST 2005 Volume 3643/2005, 614-620.

Berger, M., Weckesser, M., Weber, C., Döll, J., Morgenstern, A., Häberle, A., 2012. Solar driven cold rooms for industrial cooling applications. Energy Procedia 30, 904-911.

Bermejo, P., Pino, F. J., Rosa, F., 2010. Solar absorption cooling plant in Seville. Solar Energy 84, 1503-1512.

Beschi, M., Berenguel, M., Visioli, A., Guzman, J. L., Yebra, L., 2013. Implementation of feedback linearization gpc control for a solar furnace. Journal of Process Control 23(10), 1545-1554.
Camacho, E. F., Berenguel, M., 2012. Control of solar energy systems. In: 8th IFAC Symposium on Advanced Control of Chemical Processes. Singapore, pp. 848-855.

Camacho, E. F., Berenguel, M., Rubio, F., Martínez., D., 2012. Control of Solar Energy Systems. Springer-Verlag.

Camacho, E. F., Berenguel, M., Rubio, F. R., 1994. Application of a gain scheduling generalized predictive controller to a solar power plant. Control Engineering Practice 2, 227-238.

Camacho, E. F., Berenguel, M., Rubio, F. R., 1997. Advanced control of solar power plants. Springer Verlag, London.

Camacho, E. F., Bordons, C., 2004. Model Predictive Control, 2nd Edition. Springer Verlag.

Camacho, E. F., Gallego, A. J., 2013. Optimal operation in solar trough plants: a case study. Solar Energy 95, 106-117.

Camacho, E. F., Rubio, F. R., Berenguel, M., Valenzuela, L., 2007. A survey on control schemes for distributed solar collector fields. part i: Modeling and basic control approaches. Solar Energy 81, 1240-1251.

Camacho, E. F., Rubio, F. R., Berenguel, M., Valenzuela, L., 2007b. A survey on control schemes for distributed solar collector fields. part ii: Advanced control approaches. Solar Energy 81, 1252-1272.

Camacho, E. F., Rubio, F. R., Hughes, F., 1992. Self-tuning control of a solar power plant with a distributed collector field. IEEE Control Systems 0272- 1708/92/, 72-78.

Camacho, E. F., Samad, T., Garcia-Sanz, M., Hiskens, I., 2011. Control for renewable energy and smart grids. Tech. rep., IEEE Control Systems Society. URL Www. ieeecss . org.

Carmona, R., 1985. Analysis, modeling and control of a distributed solar collector field with a one-axis tracking system. Ph.D. thesis, Universidad de Sevilla.

Chemisana, D., López-Villada, J., Coronas, A., Rosell, J. I., Lodi, C., 2013. Building integration of concentrating systems for solar cooling applications. Applied Thermal Engineering 50 (2), 14721479

Cirre, C. M., Berenguel, M., Valenzuela, L., Camacho, E. F., 2007. Feedback linearization control for a distributed solar collector field. Control Engineering Practice 15, 1533-1544.

Clarke, D., Mohtadi, C., Tuffs, P., 1987a. Generalized Predictive Control - part I. the basic algorithm. Automatica 23 (2), 137-148.

Clarke, D., Mohtadi, C., Tuffs, P., 1987b. Generalized Predictive Control - Part II. Extensions and Interpretations. Automatica 23 (2), 149-160.

Döll, J., Bentaher, H., Mongerstern, A., 2014. First results of a pilot installation of a solar thermally driven cold store. International Journal of Refrigeration 39, 77-85.

Gallego, A. J., Fele, F., Camacho, E. F., Yebra, L. J., 2013. Observerbased model predictive control of a solar trough plant. Solar Energy 97, 426-435.

Goswami, D. Y., Kreith, F., Kreider, J. F., 2000. Principles of Solar Engineering, 2nd Edition. Taylor\&Francis.

Häberle, A., Luginsland, F., Zahler, C., Berger, M., Rommel, M., Henning, H. M., Guerra, M., De-Paoli, F., Motta, M., Apprile, M., 2007. A linear concentrating fresnel collector driving a nh3h20 absorption chiller. In: International Conference Solar AirConditioning. Tarragona (Spain).

Karamali, M., Khodabandeh, M., 2017. A distributed solar collector field temperature profile control and estimation using inlet oil temperature and radiation estimates based on iterative extended kalman filter. Renewable Energy 101, 144-155.

Khoukhi, B., Tadjine, M., Boucherit, M. S., 2015. Nonlinear continuous-time generalized predictive control of solar power plant. International Journal for Simulation and Multidisciplinary Design Optimization A3 (6), 1-12.

Kima, D., Infante-Ferreira, C., 2008. Solar refrigeration options a 
state-of-the-art review. International Journal of Refrigeration 31, $3-15$.

Leith, D. J., Leithead, W. E., 2000. Survey of gain-scheduling analysis and design. International Journal of Control 73 (11), 1001-1025.

Lemos, J. M., Neves-Silva, R., Igreja, J. M., 2014. Adaptive Control of Solar Energy Collector Systems. Springer-Verlag.

Limon, D., Alvarado, I., Alamo, T., Ruíz, M., Camacho, E. F., 2008. Robust control of the distributed solar collector field Acurex using MPC for tracking. Proceedings of the 17th World Congress The International Federation of Automatic Control, 958-963.

Normey-Rico, J., Bordons, C., Berenguel, M., Camacho, E. F., 1998. A robust adaptive dead-time compensator with application to a solar collector field. In: Proceedings of the IFAC Linear Time Delay Systems Workshop. Grenoble (France).

Pickhardt, R., 2000. Adaptive control of a solar power plant using a multi-model control. IEEE Proceedings Theory and Applications 147 (5), 493-500.

Pin, G., Falchetta, M., Fenu, G., 2007. Adaptative time-warped control of molten salt distributed collector solar fields. Control Engineering Practice 16, 813-823.

Pino, F. J., Caro, R., Rosa, F., Guerra, J., 2013. Experimental validation of an optical and thermal model of a linear fresnel collector system. Applied Thermal Engineering 50, 1463-1471.

Rawlings, J., Mayne, D., 2009. Model Predictive Control: Theory and Design. Nob Hill Publishing, LLC.

Robledo, M., Escano, J. M., Núnez, A., Bordons, C., Camacho, E. F., 2010. Development and experimental validation of a dynamic model for a fresnel solar collector. In: 18th IFAC World Congress. Milan (Italy).

Rodat, S., Bruch, A., Dupassieux., N., El-Mourchid, N., 2015. Unique fresnel demonstrator including ORC and thermocline direct thermal storage: operating experience. Energy Procedia 69, 16671675.

Rodat, S., Souza, J. V. D., Thebault, S., Vuillerme, V., Dupassieux, N. 2014. Dynamic simulations of fresnel solar power plants. Energy Procedia 49, 1501-1510.

Rubio, F., Camacho, E. F., Carmona, R., 2006. Control de campos de colectores solares. RIAI Revista Iberoamericana de Automatica e Informatica Industrial 3, 26-45.

Sonntag, C., Ding, H., Engell, S., 2008. Supervisory control of a solar air conditioning plant with hybrid dynamics. European Journal of Control 6, 451-463.

Spoladore, M., Camacho, E. F., Valcher, M. E., 2011. Distributed parameters dynamic model of a solar fresnel collector field. In: Proceedings of the IFAC 18th World Congress. IFAC World Congress (18). No. 18. pp. 14784-14790.

Witheephanich., K., Escano, J. M., Bordóns, C., 2014. Control strategies of a solar cooling plant with fresnel collector: a case study. In: International Electrical Engineering Congress IEEECON. Chonburi (Thailand).

Witheephanich, K., Escano, J. M., Gallego, A. J., Camacho, E. F., 2013. Pressurized water temperature of a fresnel collector field type cooling system using explicit model predictive control. In: Proceedings of the IASTED conference. Thailand.

Yield, A., 2017. URL http: / / www . atlanticayield.com/

Zhou, L., Li, X., Zhao, Y., Dai, Y., 2017. Performance assessment of a single/double hybrid effect absorption cooling system driven by linear fresnel solar collectors with latent thermal storage. Solar Energy 151, 82-94. 